\title{
EVOLUÇÃO MICROESTRUTURAL DURANTE O PROCESSO DE RECOZIMENTO DE UM AÇO BAIXO CARBONO COM MICRO-ADIÇÃO DE NIÓBIO E MOLIBDÊNIO LAMINADO A FRIO*
}

Mônica Aline Magalhães Gurgel ${ }^{1}$ Andersan dos Santos Paula² Rodrigo Rocha de Meira ${ }^{3}$ Fernando Generoso Neiva Ferreira ${ }^{4}$

\section{Resumo}

O presente trabalho estudou a evolução microestrutural durante o recozimento no campo intercrítico de um aço baixo carbono com micro-adição de nióbio e molibdênio, laminado a frio, destinado a indústria automobilística, sendo este material da classe dos aços bifásicos. Com o intuito de verificar se os parâmetros utilizados no processo de fabricação (laminação a quente e a frio em função de uma determinada composição química) foram definidos de forma eficaz para obtenção da microestrutura esperada para um material "Dual Phase". Os estudos foram suportados pelas análises da evolução microestrutural durante o processo de recozimento em escala laboratorial e análise dilatométrica, com o objetivo de determinar a faixa de temperatura no tratamento de recozimento em que as melhores propriedades foram atingidas. As caracterizações microestruturais e mecânicas foram avaliadas por Microscopia Óptica, Microscopia Eletrônica de Varredura (MEV) e ensaios de dureza Vickers.

Palavras-chave: Aço Bifásico; Recozimento Intercrítico; Caracterização Microestrutural.

\section{MICROSTRUCTURAL EVOLUTION DURING INTERCRITIC ANNEALING PROCESS OF A COLD ROLLED LOW CARBON STEEL WITH NIOBIUM AND MOLYBDENUM MICRO-ADDITION}

\section{Abstract}

The present work studied the microstructural evolution during the annealing in the intercritic field of a cold rolled low carbon steel with molybdenum and niobium microaddition, for automobilist applications, associated to the Dual Phase steels. In order to verify the parameters used in the thermomechanical process (hot and cold rolling in function of a particular chemical composition) were defined effectively to obtaining the expected dual phase microstructure. The studies were supported by the analysis of microstructural evolution during the annealing process in laboratory scale and dilatometer analysis, in order to determine the temperature range on the annealing treatment in which the best properties were achieved. The microstructural and mechanical characterizations were evaluated by optical microscopy, scanning electron microscopy (SEM) and Vickers hardness tests.

Keywords: Dual Phase; Intercritic Annealing; Microstructural Characterization.

1 Engenheira Metalurgista, Mestranda da PPGEM/UFF, Volta Redonda/RJ, Brasil.

2 Engenheira Metalurgista. D.Sc., Professora Adjunta da UFF/EEIMVR/VMT e PPGEM, Volta Redonda/RJ, Brasil.

3 Engenheiro Metalurgista. M.Sc. Eng. Especialista de Desenvolvimento na CSN, Volta Redonda/RJ, Brasil.

4 Engenheiro Metalurgista. M.Sc. Eng. de Desenvolvimento na CSN, Volta Redonda/RJ, Brasil.

\footnotetext{
* Contribuição técnica ao $51^{\circ}$ Seminário de Laminação - Processos e Produtos Laminados e Revestidos, 28 a 31 de outubro de 2014, Foz do Iguaçu, PR, Brasil.
} 


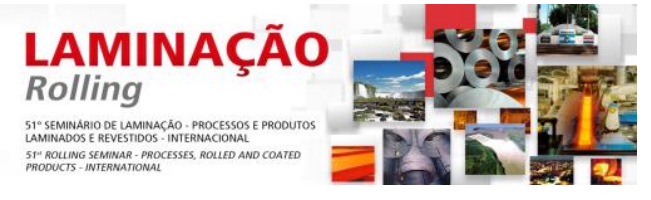

\section{INTRODUÇÃO}

Devido as exigências da indústria automobilística entre as quais destacam-se a redução do consumo de combustíveis, o aumento da segurança dos passageiros unidos a uma maior preocupação com as questões ambientais e o desenvolvimento de materiais sucedâneos, fizeram com que a siderurgia desenvolvesse aços de maior valor tecnológico. Assim, surgiram os novos aços especiais capazes de substituir os aços ao carbono convencionais, os aços AHSS "Advanced High Strength Steel" (Aços Avançados de Alta resistência), como o "Dual Phase" (DP) e os "Transformation Induced Plasticity" (TRIP). Esses aços, proporcionaram obter uma estrutura mais leve devido à redução de material com simultâneo aumento de tenacidade. No final da década de 70 , foi desenvolvido o primeiro tipo de material nesse sentido, aços DP, como uma solução alternativa, possuindo grandes vantagens quando comparado aos aços convencionais, pois combinam alta resistência mecânica e boa conformabilidade. As propriedades mecânicas desses aços estão diretamente relacionadas às suas características microestruturais: tipo, quantidade, morfologia e distribuição dos constituintes, que, por sua vez, dentre outros aspectos, dependem dos parâmetros de processamento utilizados, principalmente no recozimento contínuo. Esses aços se caracterizam por uma microestrutura normalmente constituída de ilhas de martensita dispersas em uma matriz ferrítica. Entretanto, pequenas quantidades de outras fases ou constituintes, tais como bainita, perlita e/ou austenita retida podem também estar presentes [1]. Esses aços apresentam fluxo contínuo no escoamento (ausência de patamar), baixa razão elástica (limite de escoamento/limite de resistência), elevada taxa de encruamento para baixas deformações e altos níveis de alongamento para a sua classe de resistência [2]. Os aços "dual-phase" combinam alta resistência e ductilidade relativamente alta quando comparado aos outros tipos de aços automotivos possibilitando assim a utilização de chapas estruturais com menores espessuras e consequentemente redução no peso dos mesmos.

As microestruturas mais complexas que as ferríticas, normalmente presentes nas ligas comuns de baixo $C$, são responsáveis por maximizar simultaneamente a ductilidade e a resistência mecânica dos aços. Essa abordagem está baseada nas interações mais complexas que ocorrem entre vários constituintes presentes na microestrutura, os quais, por sua vez, também devem apresentar variações significativas de dureza entre si. O aço DP ferrítico-martensítico como seu nome já diz, apresenta microestrutura constituída por uma matriz com 80 a $85 \%$ de ferrita poligonal macia somada a 15 a $20 \%$ de martensita dura, na forma de ilhas dispersa na matriz [3].

Este trabalho teve como objetivo a avaliação da evolução microestrutural durante o processo de recozimento, no campo intercrítico, em escala laboratorial de um aço baixo carbono com micro-adição de nióbio e molibdênio na condição laminada a frio, destinado à produção de chapas de aço DP laminadas a frio e galvanizadas.

Neste trabalho, analisaram-se amostras do aço em estudo na forma de placa, chapa laminada a quente, chapa laminada a frio e recozida, esta última em escala laboratorial, com composição química específica, para avaliação da evolução microestrutural via microscopia (óptica e eletrônica de varredura) e da propriedade mecânica dureza com auxílio de um microdurômetro. Bem como, análise crítica em função da taxa de aquecimento quanto a ocorrência dos fenômenos de recuperação, recristalização e transformação de fase perlita/ferrita para austenita, durante o

\footnotetext{
* Contribuição técnica ao $51^{\circ}$ Seminário de Laminação - Processos e Produtos Laminados e Revestidos, 28 a 31 de outubro de 2014, Foz do Iguaçu, PR, Brasil.
} 


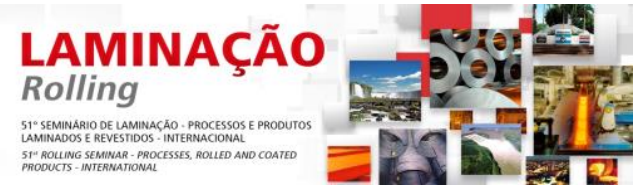

aquecimento, via análise de dilatometria em um equipamento de análise termomecânica (TMA), em amostras extraídas da chapa laminada a frio "Full-Hard".

\section{MATERIAL E MÉTODOS}

\subsection{Material}

O material em estudo refere-se a um aço baixo carbono com micro-adição de nióbio e molibdênio, provenientes de amostras processadas em escala industrial na Usina Presidente Vargas (UPV) - Companhia Nacional Siderúrgica (CSN), na forma de chapa laminada a frio - 1,20 mm de espessura (após a laminação a frio (LF)), oriunda de uma chapa laminada a quente de $3,00 \mathrm{~mm}$ de espessura. Por questões de sigilo industrial, a composição química do material está representada pelas faixas de percentual em peso dos principais elementos que definem a liga na Tabela 1.

Tabela 1. Especificação da composição química do material em estudo.

\begin{tabular}{cccccccc}
\hline \multicolumn{7}{c}{ Composição Química (\% em peso) } \\
\hline $\mathrm{C}$ & $\mathrm{Mo}$ & $\mathrm{Nb}$ & $\mathrm{Ni}$ & $\mathrm{Mn}$ & $\mathrm{Cr}$ & $\mathrm{Si}$ & $\mathrm{Al}$ \\
\hline $0,11-$ & $0,10-$ & 0,030 & 0,10 & $1,60-$ & 0,10 & 0,05 & 0,010 \\
0,15 & 0,30 & máx & máx & 1,80 & máx & máx & mín \\
\hline
\end{tabular}

Nas tabelas 2 e 3 são apresentados os valores da dureza das condições prévias de processamento (placa lingotada, chapa laminada a quente (LQ) e inclusive laminada a frio (LF)) do material em estudo e bem como os aspectos microestruturais da chapa laminada a frio, com base nos estudos de Gurgel [4]. Segundo Gurgel, na amostra da chapa laminada a quente observou-se uma homogeneização e refino microestrutural se comparado a condição microestrutural da placa, onde apresenta grãos de ferrita livre com morfologia acicular, presença de perlita fina, bainita, e constituinte MA (Martensita-Austenita).

Tabela 2. Valores médios de dureza e desvio padrão do material em estudo nas condições prévias de processamento [4].

\begin{tabular}{cccc}
\hline Dureza Vickers $\left(\mathrm{kgf} / \mathrm{mm}^{2}\right)$ & Placa & LQ & LF \\
\hline Média & 139 & 185 & 234 \\
\hline Desvio Padrão & 8 & 15 & 12 \\
\hline
\end{tabular}

Tabela 3. Fração Volumétrica a partir da análise microestrutural da amostra laminada a quente [4].

\begin{tabular}{c|c|c}
\hline \multicolumn{3}{|c}{ Fração Volumétrica (\%) } \\
\hline Ferrita & Ferrita acicular & Segunda Fase \\
\hline Segunda Fase & 49,2 & 50,8 \\
\hline
\end{tabular}

\subsection{Métodos}

\subsubsection{Curva de Recristalização e Análise Dilatométrica}

A partir da chapa LF foram confeccionados 28 corpos de prova (CPs) com $70 \mathrm{~mm}$ de comprimento (DL - Direção de Laminação) x $50 \mathrm{~mm}$ de largura (DT - Direção Transversal), dois para cada temperatura de encharque do tratamento térmico de recozimento a se proceder para levantamento de uma curva de recristalização. Este tratamento térmico foi conduzido em escala laboratorial, em fornos de tratamento térmico do tipo MUFLA, instalado nos laboratórios do Centro de Pesquisa da CSN. De modo a garantir que a taxa de aquecimento fosse alta o suficiente de modo a

\footnotetext{
* Contribuição técnica ao $51^{\circ}$ Seminário de Laminação - Processos e Produtos Laminados e
} Revestidos, 28 a 31 de outubro de 2014, Foz do Iguaçu, PR, Brasil. 


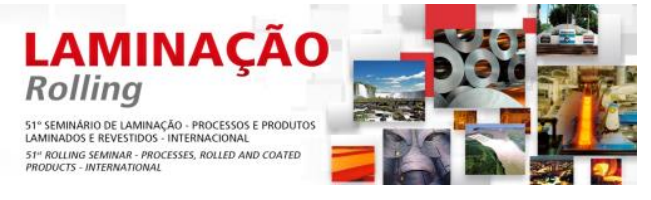

simular o recozimento contínuo em escala industrial, onde as taxas de aquecimento praticadas para este tipo de material são de da ordem de $4^{\circ} \mathrm{C} / \mathrm{s}\left(240^{\circ} \mathrm{C} / \mathrm{min}\right)$, as amostras foram introduzidas no forno pré-aquecido nas temperaturas objetivadas para o encharque de 680 a $870^{\circ} \mathrm{C}$ sendo mantidas no forno por 3 minutos, em seguida transferidas para outro forno a $600^{\circ} \mathrm{C}$ por 10 minutos (a fim de simular o superenvelhecimento da galvanização) e por fim resfriadas até temperatura ambiente ao ar. As temperaturas de encharque foram definidas com base nas temperaturas $A_{c 1} \approx 720^{\circ} \mathrm{C}$ e $A_{c 3} \approx 850^{\circ} \mathrm{C}$ (início e fim para transformação em austenita no aquecimento fora do equilíbrio) para o aço em estudo, calculadas por Ferreira [5] - segundo as equações (1) e (2) desenvolvidas por Trzaska e Dobrzanski [6]. De modo a se ter condições de temperatura de encharque inferior a $A_{c 1}$ calculado (680 e $700^{\circ} \mathrm{C}$ ), entre e inclusive $A_{c 1}$ e $A_{c 3}$ calculados $(720,730,740$, $750,770,810,830$ e $\left.850^{\circ} \mathrm{C}\right)$, e superior a $\mathrm{A}_{\mathrm{c} 3}$ calculado $\left(870^{\circ} \mathrm{C}\right)$.

$$
\begin{gathered}
A c_{1}\left[{ }^{\circ} \mathrm{C}\right]=739-22,8 \cdot \mathrm{C}-6,8 \cdot \mathrm{Mn}+18,2 \cdot \mathrm{Si}+11,7 \cdot \mathrm{Cr}-15 \cdot \mathrm{Ni}-6,4 \cdot \mathrm{Mo}-5 \cdot \mathrm{V}-28 \cdot \mathrm{Cu} \\
A c_{3}\left[{ }^{\circ} \mathrm{C}\right]=937,3-224,5 \cdot \sqrt{\mathrm{C}}-17 \cdot \mathrm{Mn}+34 \cdot \mathrm{Si}-14 \cdot \mathrm{Ni}+21,6 \cdot \mathrm{Mo}+41,8 \cdot \mathrm{V}-20 . \mathrm{Cu}
\end{gathered}
$$

Com o intuito de observar as temperaturas associadas aos processos de restauração da estrutura deformada, por meio de recuperação e recristalização da mesma, e transformação de fase $\alpha \rightarrow \gamma$, bem como a influência de distintas taxas de aquecimento nestes fenômenos, foram realizados ensaios de dilatometria em um equipamento de análise termomecânica (TMA) da marca Shimadzu, modelo TMA60. Para assim comprovar que toda a modificação estrutural em estudo (recristalização e transformação de fase) deu-se somente na etapa de encharque nos tratamentos térmicos realizadas, ou seja, inibição destes fenômenos durante a etapa de aquecimento - caracterizando assim a configuração do recozimento contínuo. Os corpos de prova para estas análises tiveram dimensões aproximadas de $5 \times 5 \times 1,5 \mathrm{~mm}$, e foram imersos em uma solução de $50 \%$ de ácido nítrico $\left(\mathrm{HNO}_{3}\right)$ e $50 \%$ de ácido Fluorídrico (HF) durante aproximadamente 10 minutos, de modo a remover a camada encruada formada pelo corte de precisão em disco diamantado. Para tal ensaio, aqueceu-se corpos de provas do aço na condição laminada a frio "Full Hard" da temperatura ambiente até a temperatura de $900^{\circ} \mathrm{C}$ com três taxas de aquecimento distintas: $15^{\circ} \mathrm{C} / \mathrm{min}, 30^{\circ} \mathrm{C} / \mathrm{min}$ e $90^{\circ} \mathrm{C} / \mathrm{min}$, e posterior resfriamento natural.

\subsubsection{Caracterização Microestrutural e Mecânica}

Para a análise metalográfica foi realizado primeiramente o processo de lixamento com lixas de carbeto de silício (220, 320, 400, 600 e 1200 mesh), fazendo uso de água como lubrificante. O polimento foi manual e realizado em uma politriz com pano de feltro e pasta de diamante nas granulometrias de 6,3 e $1 \mu \mathrm{m}$, com lubrificante Azul da Arotec para Ferrosos. Para análise da morfologia das microestruturas obtidas, as amostras foram atacadas com Nital 3\% (3\% de ácido nítrico e $97 \%$ de álcool etílico PA), por esfregamento por 6 segundos, ou até que as amostras ficassem foscas.

A quantificação de fração da ferrita recristalizada e segunda fase nas amostras com evidência de recristalização, após o ataque de Nital 3\%, foi realizada com o auxílio da ferramenta "Phase" do módulo "Materials - Pró" do programa "Image Pro Plus". As amostras foram observadas utilizando-se um Microscópio Optico (MO), equipamento Olympus GX71 acoplado a uma câmera digital e controlado pelo

\footnotetext{
* Contribuição técnica ao $51^{\circ}$ Seminário de Laminação - Processos e Produtos Laminados e Revestidos, 28 a 31 de outubro de 2014, Foz do Iguaçu, PR, Brasil.
} 


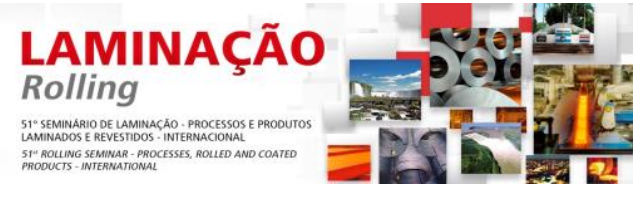

software "Image Pro Plus", instalado na Escola de Engenharia Industrial Metalúrgica de Volta Redonda (EEIMVR) da Universidade Federal Fluminense (UFF).

A análise quanto a morfologia e quantificação de fases das amostras recozidas, de 740 a $870^{\circ} \mathrm{C}$, foi realizada um Microscópio Eletrônico de Varredura (MEV) da marca FEI, modelo QUANTA 3D com filamento de FEG (Emissão por efeito de campo), instalado Centro de Pesquisa da CSN. Os parâmetros utilizados para análise com os detectores de elétrons secundários (SE) e Espectroscopia de Energia Dispersiva de Raios-X (EDS) foram: tensão de aceleração de 10 kV, "spot size" de 5,5, e distância de trabalho entre 7,3 e $10 \mathrm{~mm}$. A análise das amostras recozidas, de 680 a $730^{\circ} \mathrm{C}$, foi realizada em um MEV da marca Carl Zeiss, modelo EVO MA10 com filamento de Tungstênio, instalado na EEIMVR da UFF, com os seguintes os parâmetros para o detector de SE: tensão de aceleração de 20 kV, "spot size" de 520 e distância de trabalho entre 10,5 e $11 \mathrm{~mm}$. A avaliação do tamanho de grão ferrítico, para as amostras completamente recristalizadas, foi feita pelo método de interceptos de Heyn (ou método linear), com imagens obtidas por microscopia ótica com aumento de 1000x, pela equação (3).

$$
L=\frac{\mathrm{V}\left(\frac{\mathrm{LT}}{\mathrm{M}}\right)}{\mathrm{Na}}
$$

Onde, L é o tamanho de grão médio $(\mathrm{mm}), \mathrm{V}$ é a Fração volumétrica ferrítica, LT é o comprimento da linha base de medida $(\mathrm{mm}), \mathrm{M}$ é o aumento, e $\mathrm{Na}$ é o número de interceptos. Foram feitas medidas de dureza Vickers em um microdurômetro Ernst Leitz, base na equação (4) em todas as amostras, com carga máxima de 40 gf e o tempo de permanência na carga máxima de 20 segundos. Com realização de 10 medições por amostra, distribuídas ao longo de $1 / 4$ da espessura da chapa, em seguida obteve os valores da dureza através da média aritmética das medidas e seus respectivos desvios padrão.

$$
H V=\frac{1,8544 Q}{L^{2}}
$$

Onde, $Q$ é a carga (gf), $L$ é a média das diagonais da impressão da identação $(\mu \mathrm{m})$ e HV é a dureza Vickers $\left(\mathrm{Kgf} / \mathrm{mm}^{2}\right)$.

\section{RESULTADOS E DISCUSSÃO}

A fim de observar a forma como se deram os processos de recuperação, recristalização e transformação de fase durante o aquecimento, foram realizadas análises de dilatometria (Figura 1) do material laminado a frio "Full Hard" submetido a três taxas de aquecimento de $15^{\circ} \mathrm{C} / \mathrm{min}, 30^{\circ} \mathrm{C} / \mathrm{min}$ e $90^{\circ} \mathrm{C} / \mathrm{min}$. Comparando as curvas apresentadas no gráfico da Figura 1 pode-se verificar:

- Na taxa de $15^{\circ} \mathrm{C} / \mathrm{min}$ pode-se claramente verificar as evidencias dos fenômenos de recuperação e recristalização da estrutura encruada, conforme a curva verde da Figura 1. Pode-se inferir que o fenômeno de recuperação inicia-se em aproximadamente $400^{\circ} \mathrm{C}$, o qual promove uma expansão pouco significativa no material. De $400^{\circ} \mathrm{C}$ até aproximadamente $700^{\circ} \mathrm{C}$ nesta taxa de aquecimento tem-se a continuidade da recuperação da estrutura. Acima de $700^{\circ} \mathrm{C}$ até $830^{\circ} \mathrm{C}$ começa a tomar parte o fenômeno de recristalização, o qual promove uma expansão mais significativa no material. Em temperatura em torno de $830^{\circ} \mathrm{C}$ têm-se indícios da transformação de fase pela formação de austenita em conjunto com a continuidade da recristalização, tendo em vista que a transformação de estrutura CCC para CFC

\footnotetext{
* Contribuição técnica ao $51^{\circ}$ Seminário de Laminação - Processos e Produtos Laminados e Revestidos, 28 a 31 de outubro de 2014, Foz do Iguaçu, PR, Brasil.
} 


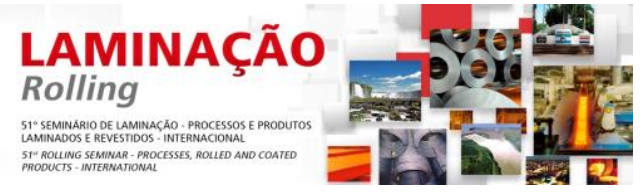

dá-se por contração, o que justifica neste ponto ocorrer uma suavização na expansão da amostra.

- Na taxa de $30^{\circ} \mathrm{C} / \mathrm{min}$ (curva azul, Figura 1), verifica-se a ocorrência dos fenômenos de recuperação e recristalização da estrutura encruada para temperaturas mais elevadas, inviabilizando a ocorrência da transformação de fase abaixo de $900^{\circ} \mathrm{C}$.

- Finalmente, na taxa de aquecimento mais alta $\left(90^{\circ} \mathrm{C} / \mathrm{min}\right)$ (curva vermelha, Figura 1), a ocorrência do fenômeno de recuperação também se deslocou para temperatura mais elevadas, fazendo com que a recristalização só se inicia em torno de $850^{\circ} \mathrm{C} / \mathrm{min}$, inviabilizando o término da recristalização e ausência de qualquer transformação de fase na temperatura máxima adotada no ensaio de dilatometria $\left(900^{\circ} \mathrm{C}\right)$.

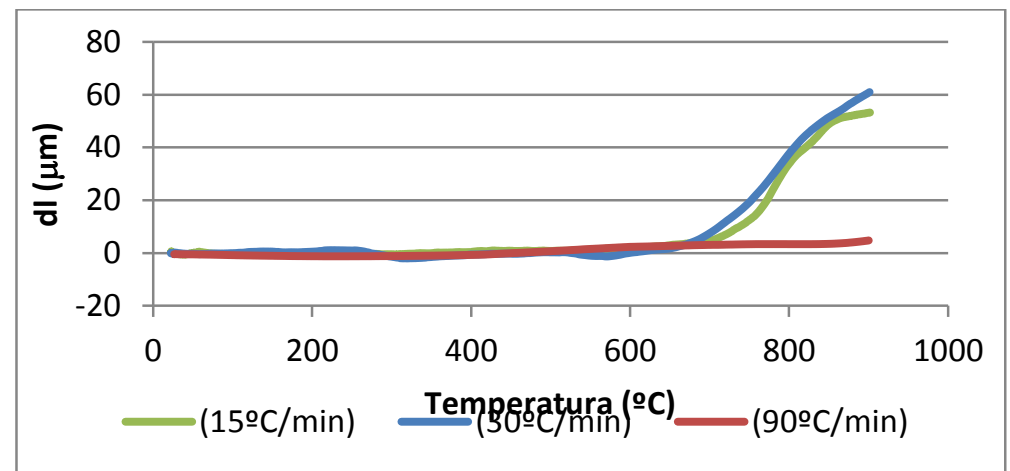

Figura 1. Análise de dilatometria em amostras de chapa na condição laminada a frio "Full Hard", com taxas de aquecimento de 15,30 e $90^{\circ} \mathrm{C} / \mathrm{min}$.

Estes resultados permitem assim dizer que nos tratamentos térmicos adotados em escala laboratorial e nas condições de recozimento contínuo em escala industrial onde tem-se taxas superiores, que a recristalização e a transformação de fase pela formação de austenita irá se dar ao longo do patamar na temperatura de encharque e não durante a etapa de aquecimento. Evidencias estas suportadas pela literatura $[7,8]$, em que relatam que quanto maior a taxa de aquecimento adotada menor é o potencial termodinâmico para a recuperação da estrutura encruada e maior para a recristalização, aumentando assim a possibilidade do início e prosseguimento da recristalização durante o estabelecimento da temperatura de encharque no recozimento. Características básicas que diferenciam os fenômenos presentes e produtos resultantes de tratamentos térmicos de recozimento para recristalização em fornos de recozimento contínuo (altas taxas de aquecimento conjugadas a temperaturas de encharque mais elevadas associadas a tempos de encharque mais curtos) ao invés de em fornos de recozimento em caixa. Com base nas amostras LF submetidas ao tratamento térmico de recozimento no campo intercrítico, em escala laboratorial, foram realizadas medidas de dureza Vickers e gerada a curva de recristalização, na faixa de temperatura entre 680 e $870^{\circ} \mathrm{C}$ (Figura 5). Com o intuito de compreender estes valores, realizou-se caracterizações microestruturais qualitativa e quantitativamente, representado nas Figuras de 2 a 4 e Tabela 4, onde se verifica a gradual recristalização da ferrita em conjunto com 0 enriquecimento e posterior empobrecimento de soluto da austenita (evidenciado pela formação de martensita em função do incremento da aparente fração volumétrica e posterior co-existência com a perlita e bainita) até a completa recristalização e crescimento de grão. Com auxílio do detector de EDS no MEV foi possível confirmar a presença de carbonetos livres no interior dos grãos de ferrita livre, em toda a gama de temperatura em estudo (Figuras 2, 3 e 4) e com dimensão superior para as temperaturas mais elevadas (Figura 4). O que pode ser justificado pela presença de * Contribuição técnica ao $51^{\circ}$ Seminário de Laminação - Processos e Produtos Laminados e
Revestidos, 28 a 31 de outubro de 2014, Foz do Iguaçu, PR, Brasil. 


\section{Rolling \\ ÇAO}

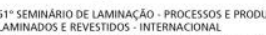

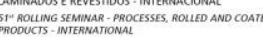

$\mathrm{Nb}$ e Mo neste aço (Tabela 1), os quais formam carbonetos com maior temperatura de dissolução que a cementita $[4,5]$.

(a)

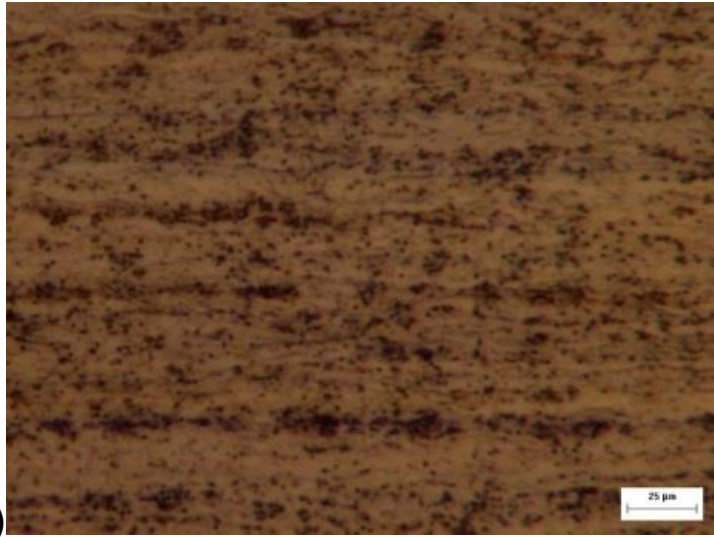

(c)

(e)
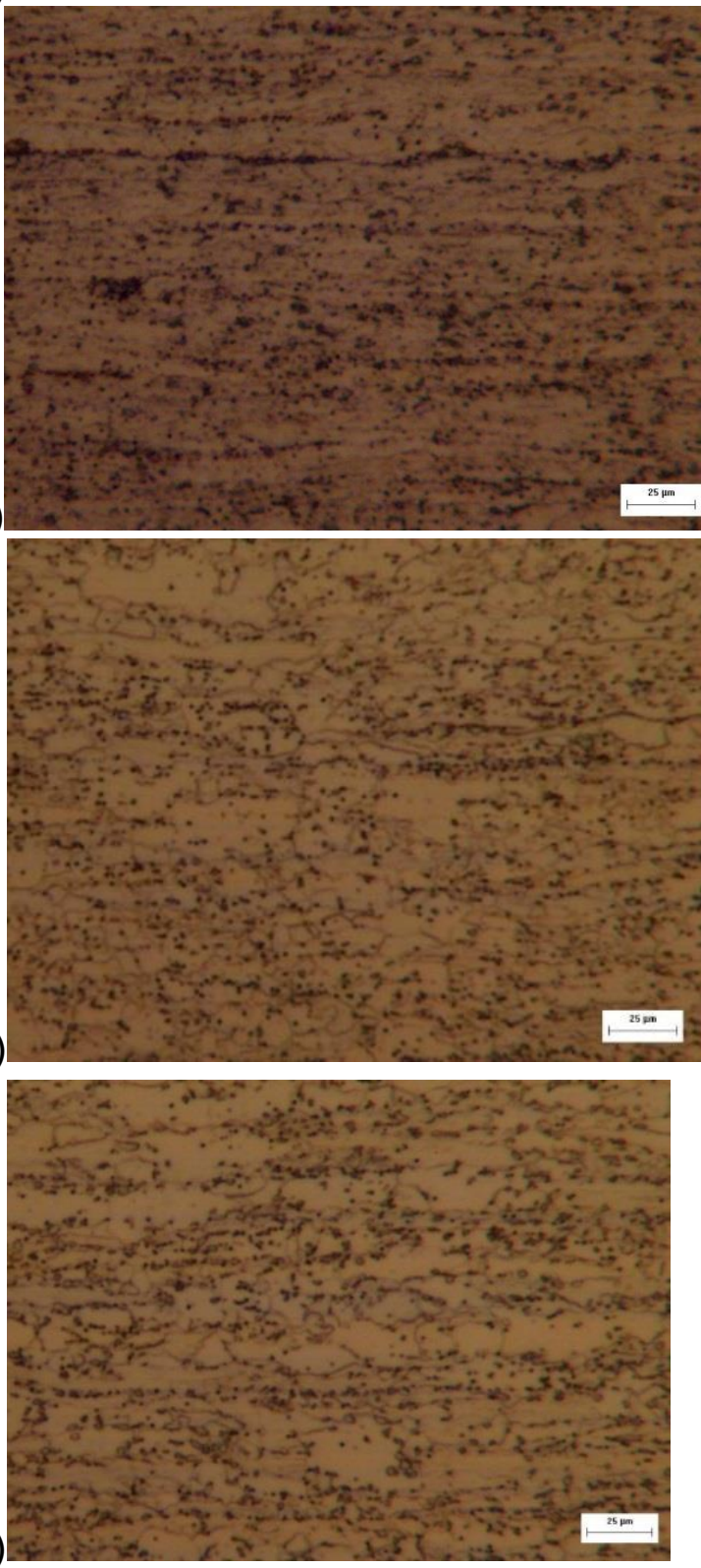

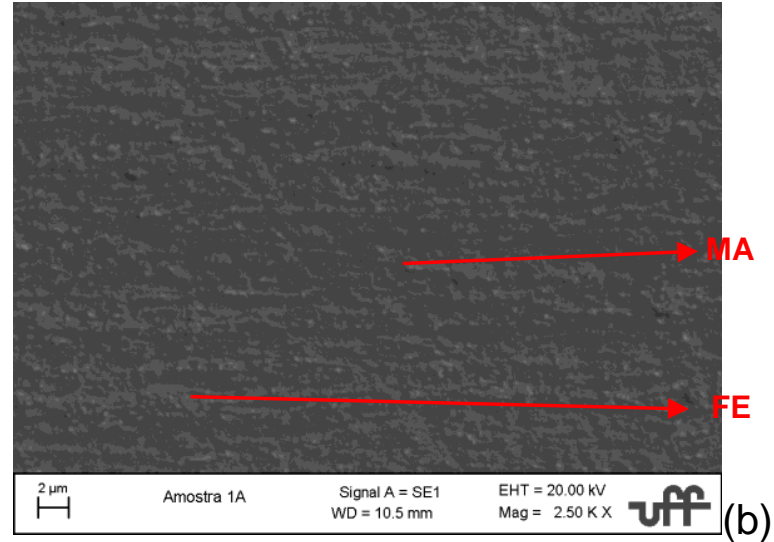

A

$E$

E

MA

\begin{tabular}{|c|c|c|c|}
\hline$\stackrel{2 \mu m}{\longmapsto}$ & Amostra 2A & $\begin{array}{l}\text { Signal } A=\text { SE1 } \\
W D=10.5 \mathrm{~mm}\end{array}$ & $\begin{array}{l}\mathrm{EHT}=20.00 \mathrm{kV} \\
\mathrm{Mag}=2.50 \mathrm{kX}\end{array}$ \\
\hline
\end{tabular}

$\mathbf{R}$

\begin{tabular}{|c|c|c|c|}
\hline$\stackrel{1}{H}^{\text {m }}$ & Amostra $5 \mathrm{~A}$ & $\begin{aligned} \text { Signal } A & =S E 1 \\
W D & =11.0 \mathrm{~mm}\end{aligned}$ & $\begin{array}{l}E H T=20.00 \mathrm{kV} \\
\mathrm{Mag}=2.50 \mathrm{KX}\end{array}$ \\
\hline
\end{tabular}

Figura 2. Caracterização microestrutural das amostras recozidas nas temperatura de encharque de: $(a, b) 680^{\circ} \mathrm{C}$, (c,d) $700^{\circ} \mathrm{C}$, (e,f) $720^{\circ} \mathrm{C}$, (g,h) $730^{\circ} \mathrm{C}$. (a,c,e,g) MO. (b,d,f,h) MEV. Nital 3\%. (martensitaaustenita (MA), ferrita-encruada (FE), ferrita-recristalizada (FR)).

* Contribuição técnica ao $51^{\circ}$ Seminário de Laminação - Processos e Produtos Laminados e Revestidos, 28 a 31 de outubro de 2014, Foz do Iguaçu, PR, Brasil. 


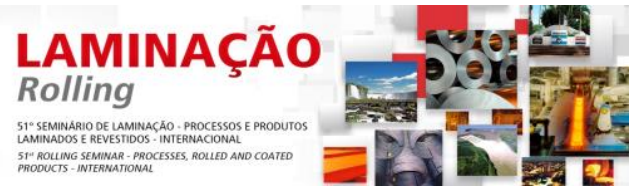

(a)
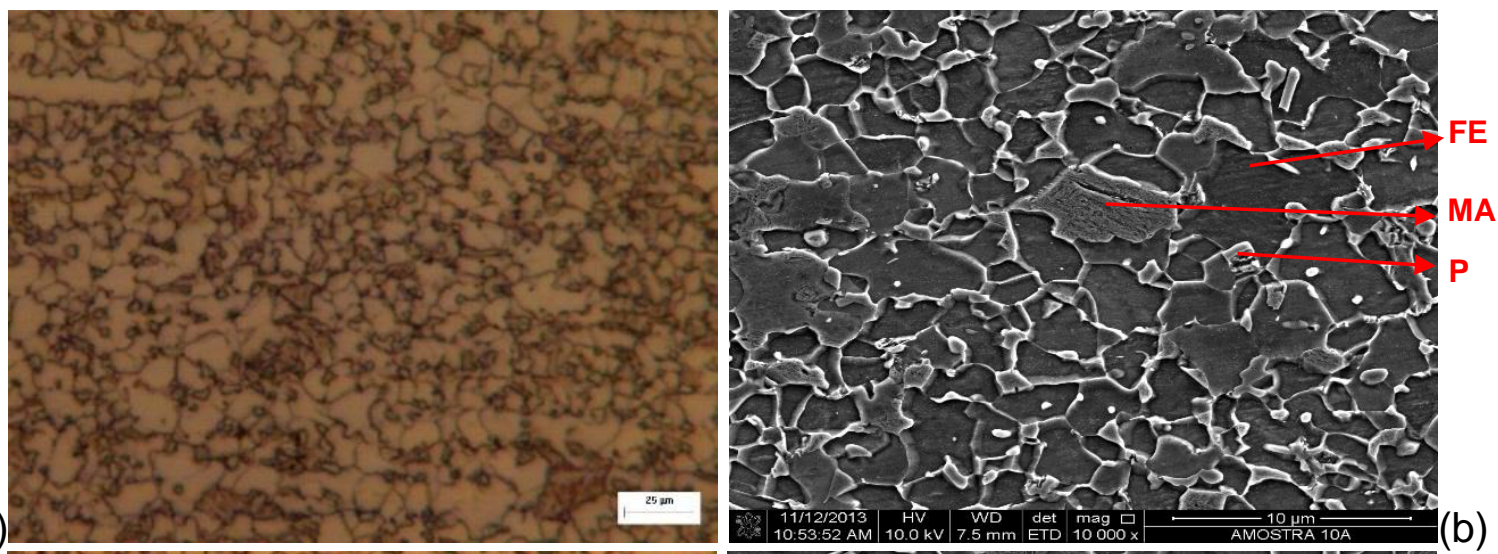

(c)
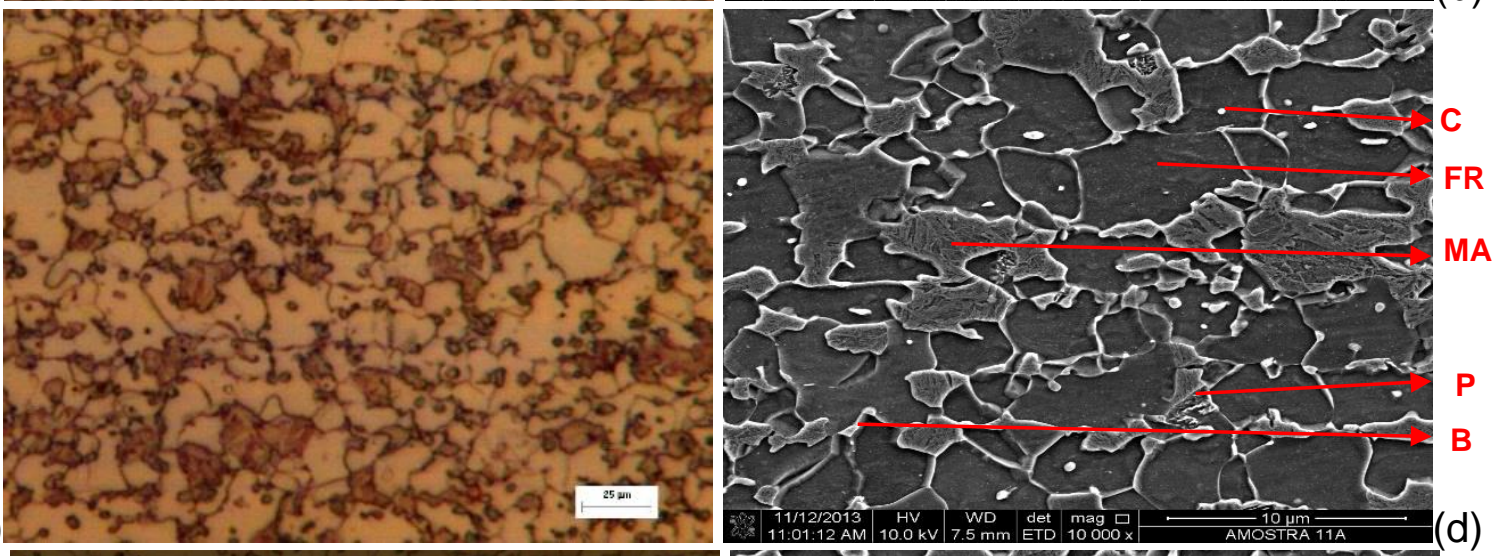

(e)
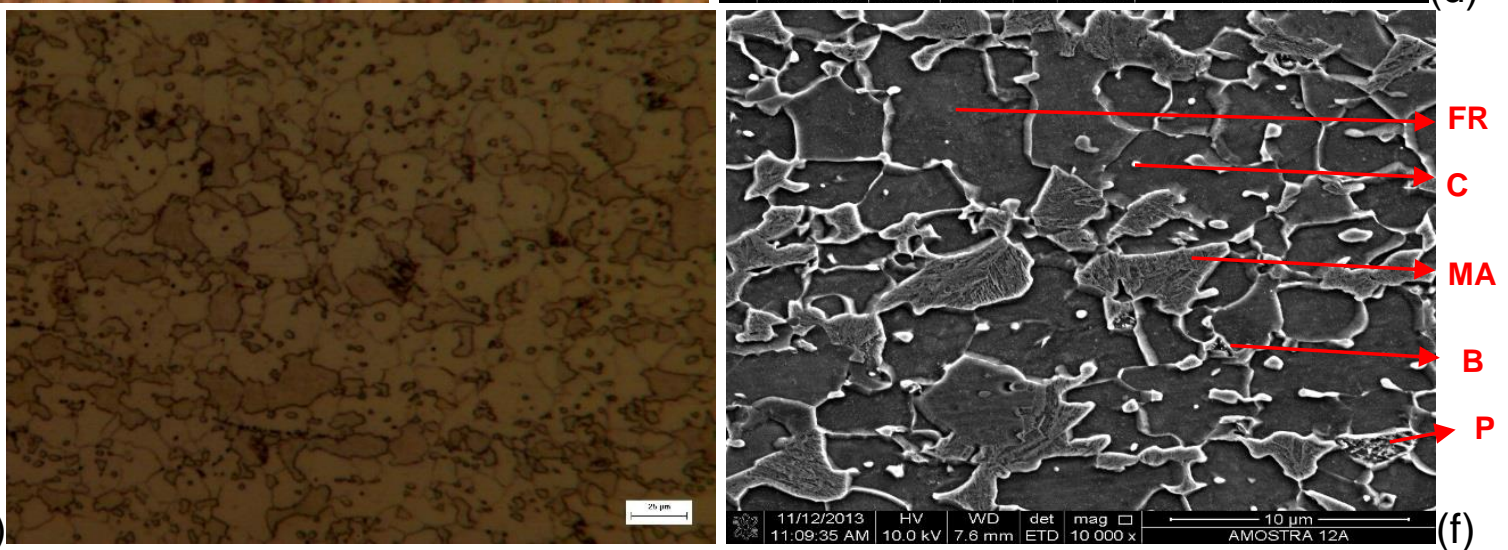

Figura 4. Caracterização microestrutural das amostras recozidas nas temperatura de encharque de: (a,b) $830^{\circ} \mathrm{C}$, (c,d) $850^{\circ} \mathrm{C}$, (e,f) $870^{\circ} \mathrm{C}$. (a,c,e) MO. (b,d,f) MEV. Nital 3\%. (perlita (P), Bainita (B), Carboneto $(\mathrm{C})$, martensita-austenita (MA), ferrita-encruada (FE), ferrita-recristalizada (FR)).

$\mathrm{Na}$ curva de recristalização, apresentada na Figura 5, é possivel identificar quatro regiões distintas em função das valores de dureza média e seus respectivos desvios padrão.

$\mathrm{Na}$ região 1, destacada na Figura 5 pelas temperaturas 680 e $700^{\circ} \mathrm{C}$ e suas respectivas microestruturas e características microestruturais (Figuras 2a,b,c,d e Tabela 4), verificou evidências de uma estrutura recuperada e do início da recristalização devido o decréscimo da dureza em comparação com a condição LF (Tabela 2). Porém a dureza manteve-se elevada, o que é justificado na análise microestrutural, no microscópio óptico, devido a ferrita manter-se em grande parte com aspecto encruado (grãos claros e alongados), algumas evidências de ferrita recristalizada (grãos claros e equiaxiais) e uma segunda fase (regiões escuras), conforme representado nas Figuras 2a,c e Tabela 4. Durante análise com auxílio do MEV para as condições recozidas a 680 e $700^{\circ} \mathrm{C}$, pode-se constatar que a segunda

* Contribuição técnica ao $51^{\circ}$ Seminário de Laminação - Processos e Produtos Laminados e Revestidos, 28 a 31 de outubro de 2014, Foz do Iguaçu, PR, Brasil. 


\section{Rolling}

fase estava atribuída à presença do constituinte MA (Martensita - Austenita) (regiões em alto relevo e claras). Estas evidências revelam que na prática a temperatura de decomposição da segunda fase formada no resfriamento na $L Q$ e presentes na condição LF, deu-se em uma temperatura inferior àquela obtida pela equação (1) $\left(A_{c 1}\right.$ calculado $\approx 720^{\circ} C$ ), isto provavelmente se deve a presença de elementos formados de carbonetos (como Nb e Mo - Tabela 1), que em parte, em conjunto com carbono formam-se precipitados isolados e distribuídos na matriz ferrítica, alterando assim a composição real do composto perlita e por consequência sua temperatura de decomposição.

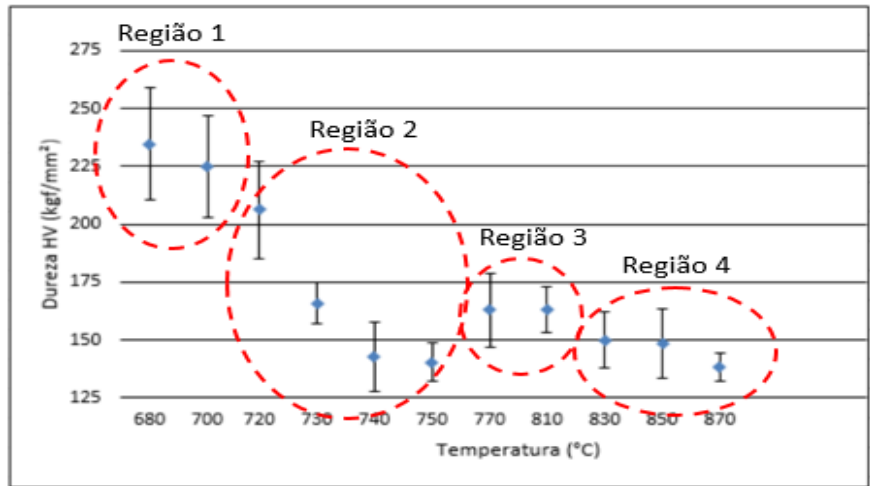

Figura 5. Curva de recristalização e subdivisão em regiões com base na evolução microestrutural.

Tabela 4. Quantificação das fases presentes das amostras recozidas, e tamanho de grão ferrítico das amostras completamente recristalizadas.

\begin{tabular}{|c|c|c|c|c|}
\hline \multirow[b]{2}{*}{$\begin{array}{l}\text { Temperatura } \\
\left({ }^{\circ} \mathrm{C}\right)\end{array}$} & \multirow[b]{2}{*}{ Resultados } & \multicolumn{2}{|c|}{ Fração Volumétrica (\%) } & \multirow{2}{*}{$\begin{array}{l}\text { Tamanho de } \\
\text { Grão } \\
\text { Ferrítico }(\mu \mathrm{m})\end{array}$} \\
\hline & & $\begin{array}{c}\text { Ferrita } \\
\text { recristalizada }\end{array}$ & $\begin{array}{l}\text { Segunda Fase em conjunto ou } \\
\text { não com Ferrita Encruada }\end{array}$ & \\
\hline \multirow{2}{*}{680} & Média & 9,5 & 90,5 & $(-)$ \\
\hline & Desvio Padrão & 2,2 & 2,2 & $(-)$ \\
\hline \multirow{2}{*}{700} & Média & 19,3 & 80,7 & $(-)$ \\
\hline & Desvio Padrão & 2,2 & 2,2 & $(-)$ \\
\hline \multirow{2}{*}{720} & Média & 30,2 & 69,8 & $(-)$ \\
\hline & Desvio Padrão & 6,4 & 6,4 & $(-)$ \\
\hline \multirow{2}{*}{730} & Média & 34,9 & 65,1 & $(-)$ \\
\hline & Desvio Padrão & 5,4 & 5,4 & $(-)$ \\
\hline \multirow{2}{*}{740} & Média & 41,0 & 59,0 & $(-)$ \\
\hline & Desvio Padrão & 4,3 & 4,3 & $(-)$ \\
\hline \multirow{2}{*}{750} & Média & 41,5 & 58,5 & $(-)$ \\
\hline & Desvio Padrão & 4,8 & 4,8 & $(-)$ \\
\hline \multirow{2}{*}{770} & Média & 45,6 & 54,4 & $(-)$ \\
\hline & Desvio Padrão & 2,8 & 2,8 & $(-)$ \\
\hline \multirow{2}{*}{810} & Média & 46,1 & 53,9 & $(-)$ \\
\hline & Desvio Padrão & 4,8 & 4,8 & $(-)$ \\
\hline \multirow{2}{*}{830} & Média & 50,6 & $49,4^{(*)}$ & 1,4 \\
\hline & Desvio Padrão & 1,2 & $1,2^{(*)}$ & 0,1 \\
\hline \multirow{2}{*}{850} & Média & 52,0 & $47,9^{(*)}$ & 1,6 \\
\hline & Desvio Padrão & 1,5 & $1,5^{(*)}$ & 0,2 \\
\hline \multirow{2}{*}{870} & Média & 56,4 & $43,6^{(*)}$ & 1,7 \\
\hline & Desvio Padrão & 2.0 & $2.0^{(*)}$ & 0.2 \\
\hline
\end{tabular}

${ }^{(-)}$Estrutura parcialmente recristalizada. ${ }^{(*)}$ Estrutura completamente recristalizada, ou seja, isenta de Ferrita encruada.

$\mathrm{Na}$ região 2, destacada na Figura 5 pelas temperaturas entre 720 e $750^{\circ} \mathrm{C}$ e suas respectivas microestruturas e características microestruturais (Figuras 2e,f,g,h e 3a,b,c,d, e Tabela 4), verificou evidências do progresso da recristalização (do início

* Contribuição técnica ao $51^{\circ}$ Seminário de Laminação - Processos e Produtos Laminados e Revestidos, 28 a 31 de outubro de 2014, Foz do Iguaçu, PR, Brasil. 


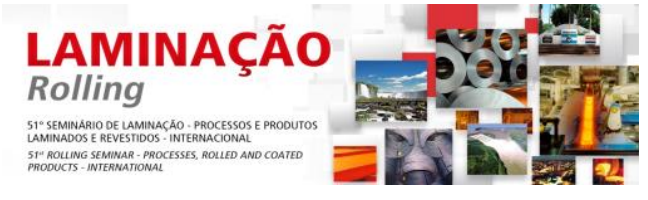

ao fim) pelo contínuo e significativo decréscimo da dureza em comparação com a condição LF (Tabela 2). Inicialmente, na amostra recozida a $720^{\circ} \mathrm{C}$, os valores de dureza mantem-se relativamente elevados, o que é justificado na análise microestrutural, no microscópio óptico, devido a ferrita manter-se em grande parte com aspecto encruado (grãos claros e alongados), apesar do incremento da fração da ferrita recristalizada (grãos claros e equiaxiais) e uma segunda fase (regiões escuras), conforme representado na Figura 2e e Tabela 4. Enquanto na amostra recozida a $730^{\circ} \mathrm{C}$ a dureza apresenta um decréscimo substancial, pelo incremento da fração de ferrita recristalizada em detrimento do decréscimo de ferrita encruada, em conjunto com a segunda fase, conforme representado na Figura $2 \mathrm{~g}$ e Tabela 4. Durante análise com auxílio do MEV para as condições recozidas a 720 e $730^{\circ} \mathrm{C}$, pode-se constatar que a segunda fase manteve-se atribuída à presença do constituinte MA (Martensita - Austenita) (regiões em alto relevo e claras), o que é justificado pelo enriquecimento de soluto na austenita até a temperatura de $730^{\circ} \mathrm{C}$ de modo a proporcionar sua alta temperabilidade e garantia da formação de somente constituinte adifusional (Martensita) durante o resfriamento em água. Por outro lado, nas amostras recozidas a 740 e $750^{\circ} \mathrm{C}$ verifica-se os menores valores de dureza, em comparação as amostras anteriormente analisadas, o que se justifica pela substancial fração de ferrita recristalizada em conjunto com alguma ferrita encruada e segunda fase, com base na análise microestrutural via microscopia óptica Figuras 3a,c e Tabela 4. Com auxílio da análise no MEV, a segunda fase é atribuída ao constituinte MA somente na temperatura de $740^{\circ} \mathrm{C}$ (Figura $3 \mathrm{~b}$ - regiões em alto relevo e claras) e em conjunto com alguma perlita na temperatura de $750^{\circ} \mathrm{C}$ (Figura 3d - MA: regiões em alto relevo e claras; e Perlita: Regiões com lamelas claras em alto relevo intercaladas por lamelas escuras em baixo relevo). $\mathrm{Na}$ região 3 , destacada na Figura 5 pelas temperaturas entre 770 e $810^{\circ} \mathrm{C}$ e suas respectivas microestruturas e características microestruturais (Figuras 3 e,f,g,h e Tabela 4), observou-se um aumento da dureza. Isto provavelmente se deve ao fato da decomposição da perlita em austenita, enriquecendo-a com soluto na temperatura de encharque, e posteriormente em martensita (no resfriamento acelerado), ser mais evidente que a recristalização da matriz ferrítica que contribui para o decréscimo da dureza. Conforme as evidências microestruturais exibidas com o auxílio da análise no MEV, onde se verifica a presença de uma maior quantidade do constituinte MA (Figura $3 f, h$ - regiões em alto relevo e claras), em relação a ferrita recristalizada (Figura $3 f, h$ - grãos claros e equiaxiais). Na região 4, destacada na Figura 5 pelas temperaturas entre 830,850 e $870^{\circ} \mathrm{C}$ e suas respectivas microestruturas e características microestruturais (Figuras 4a,b,c,d,e,f, e Tabela 4), verifica-se que 0 material está completamente recristalizado. Fator este evidenciado pelo decréscimo da dureza com o aumento da temperatura de encharque, e de maneira oposta, um aumento no desvio padrão, devido ao crescimento dos grãos ferríticos (Figura $4 b, d, f)$. Em conjunto a matriz ferrítica (grãos claros e equiaxiais), fez-se presente a martensita com morfologia mais grosseira, associada ao constituinte MA (regiões em alto relevo e claras), a perlita (regiões com lamelas claras em alto relevo intercaladas por lamelas escuras em baixo relevo) e bainita (regiões claras que nucleia-se no contorno de grão e tem formato triangular), as quais se formaram decréscimo da temperabilidade pelo empobrecimento de soluto na austenita formada na temperatura de encharque, no limite superior do campo intercrítico ou acima de $A_{c 3}$.

\footnotetext{
* Contribuição técnica ao $51^{\circ}$ Seminário de Laminação - Processos e Produtos Laminados e Revestidos, 28 a 31 de outubro de 2014, Foz do Iguaçu, PR, Brasil.
} 


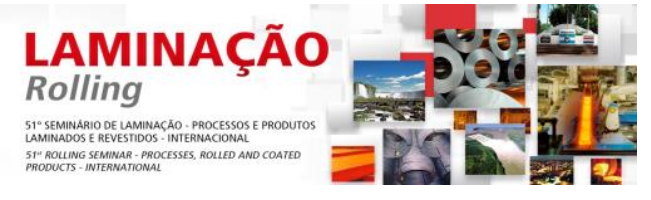

\section{CONCLUSÃO}

Os resultados obtidos permitem dizer que nos tratamentos térmicos adotados simulando o recozimento contínuo em escala laboratorial, onde tem-se taxas de aquecimento superiores ao do recozimento em caixa, que a recristalização e a transformação de fase pela formação de austenita irá se dar ao longo do patamar na temperatura de encharque e não durante a etapa de aquecimento.

O tempo de encharque de 3 minutos foi suficiente para recristalizar parcialmente e promover a formação de alguma austenita nas temperaturas de encharque até $810^{\circ} \mathrm{C}$, acima dessa temperatura verificou-se a completa recristalização, que poderia contribuir para um decréscimo nas propriedades mecânicas do material. Assim a presença de alguma fração de ferrita encruada em conjunto com o constituinte MA vem a contribuir para o aumento da resistência mecânica do aço DP em estudo. Além disso, nas análises associadas a temperaturas de encharque a partir de $830^{\circ} \mathrm{C}$ evidenciou-se o crescimento de grão ferrítico em conjunto com formação de um constituinte MA grosseiro devido ao empobrecimento de soluto na austenita formada no encharque.

\section{Agradecimentos}

Os autores agradecem a CSN por ter fornecido o material estudado, realização dos tratamentos térmicos e disponibilização das análises no MEV FEI Quanta 3D do seu Centro de Pesquisa. A UFF pelos recursos para preparação e caracterização microestrutural via microscopia óptica e mecânica do material. Ao Laboratório Multiusuário de Microscopia Eletrônica (LMME) da UFF pela utilização do MEV para análise de algumas das amostras em estudo.

\section{REFERÊNCIAS}

1 Speich GR. Physical Metallurgy of Dual-Phase Steels. In: Kot RA, Bramfitt BL. Fundamentals of Dual Phase Steels. Proceedings, AIME; ASM. 1981; 3-46.

2 Gorni AA. Aços Avançados de alta resistência: microestrutura e propriedades mecânicas - Corte e Conformação de Metais. Dezembro 2008; 3:35: 26-57.

3 Rashid MS. GM 980X - Potential Applications and Review. International Automotive Engineering Congress and Exposition. S.A.E. Technical Publication n`770211. Detroit (EUA). 1977: 12.

4 Gurgel MAM. Evolução Microestrutural Durante o Processo de Recozimento de um Aço Baixo Carbono com Micro adição de Nióbio e Molibdênio Laminado a frio. [Trabalho de Conclusão de Curso em Engenharia Metalúrgica]. Volta Redonda/RJ, Brasil: Universidade Federal Fluminense; 2013.

5 Ferreira FGN. Influência dos Parâmetros de Recozimento Intercrítico para Obtenção de Aços Bifásicos Laminados a Frio. [Dissertação de Mestrado]. Volta Redonda/RJ, Brasil: Universidade Federal Fluminense; 2014.

6 Trzaska J, Dobrzanski LA. Modelling of CCT Diagrams for Engineering and Constructional Steels. Journal of Materials Processing Technology. 2007; 192-193: 504-510.

7 Paula AS. Caracterização Estrutural Comparativa: um Aço Extra-baixo Carbono ao Boro e um Aço Livre de Intersticiais ao Titânio. [Dissertação de Mestrado]. Rio de Janeiro/RJ, Brasil: Instituto Militar de Engenharia; 2002.

8 Mohanty RR. Girina O. Fonstein NM. Effect of Heating Rate on the Austenite Formation in Low-carbon High-Strength Steels Annealed in the Intercritical Region. Metallurgical and Materials Transactions A. 2011; 42A: 3680-3690.

\footnotetext{
* Contribuição técnica ao $51^{\circ}$ Seminário de Laminação - Processos e Produtos Laminados e Revestidos, 28 a 31 de outubro de 2014, Foz do Iguaçu, PR, Brasil.
} 